\title{
STROKE PATIENTS
}

\section{Zeliha Ozlem YURUK, Assoc Prof, PT}

Baskent University, Faculty of Health Sciences, Department of Physiotherapy and Rehabilitation, Ankara, TURKEY.

\section{OBJECTIVE}

The motor, sensory and cognitive problems in stroke patients negatively affect the daily activities, quality of life and psychological state of the patients. The aim of our study was to determine the effects of the patient-specific physiotherapy and rehabilitation program based on the neurodevelopmental treatment approach on motor recovery, activities of daily living, quality of life, anxiety and depression in patients with ischemic stroke.

\section{METHODS}

Fifteen $(31.9 \%)$ female and $32(68.1 \%)$ male total of 47 ischemic stroke patients (Mini Mental State Examination score>24) were enrolled to the study between August 2010 and May 2012.

- The patients had a physiotherapy rehabilitation program based on the neurodevelopmental treatment approach for 20 sessions. This program included exercises such as strengthening for weak tonic muscles in inner range, rotation, elongation, enhancement of sensory input, functional activities and environmental modification.

- Motor Assessment Scale (MAS)

- $\quad$ Functional Independence Measure (FIM)

- $\quad$ Stroke Specific Quality of Life (SSQOL)

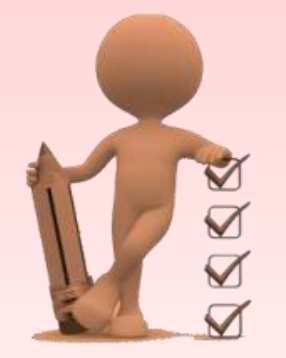

- Hospital Anxiety Depression Scale (HADS)

- $\quad$ Patient's satisfaction levels (5-question Likert-type scale).

- $\quad$ The data were analyzed using "Paired samples T test".

\section{RESULTS}

Table 1. The sociodemographical and clinical characteristics of the stroke patients

\begin{tabular}{l|c|} 
& $\begin{array}{c}\text { Treatment group } \\
(\mathrm{n}=47)\end{array}$ \\
\hline Age, mean $(\chi \pm S \mathrm{D})$, years & $58.55 \pm 12.93$ \\
\hline BMl, mean $(\chi \pm S D), \mathrm{kg} / \mathrm{m}^{2}$ & $26.81 \pm 4.26$ \\
\hline Education level, mean $(\chi \pm S \mathrm{D})$, years & $6.11 \pm 4.75$ \\
\hline Stroke duration, mean $(\chi \pm S D /$ min-max $)$ month & $16.65 \pm 26.10(2-96)$ \\
\hline Dominant side, $n(\%)$ & \\
\hline Right & $42(89.4)$ \\
\hline Left & $5(10.6)$ \\
\hline Affected extremity, $\mathrm{n}(\%)$ & \\
\hline Right & $18(38.3)$ \\
\hline Left & $29(61.7)$
\end{tabular}

SD: standard deviation, kg: kilogram, $\mathrm{m}$ : meter, $\mathrm{n}$ : number, \%: percentage, $\mathrm{BMI}=$ body mass index, MMSE: Mini mental State Examination

Table 2. Pre- and post- treatment values of the MAS, FIM, SSQOL, HADS scores

\begin{tabular}{|l|c|c|c|}
\multicolumn{1}{c|}{} & \multicolumn{3}{|c|}{ Treatment group (n=47) } \\
\cline { 2 - 4 } & Pre-treatment & Post-treatment & $p$ \\
\hline MAS & $25.39 \pm 14.43$ & $27.47 \pm 13.45$ & $0.020^{*}$ \\
\hline FIM & $90.96 \pm 24.94$ & $93.03 \pm 24.25$ & $0.000^{*}$ \\
\hline SSQOL & $3.26 \pm 0.80$ & $3.28 \pm 0.77$ & 0.773 \\
\hline HADS & & & \\
Anxiety & $6.21 \pm 4.44$ & $5.63 \pm 4.06$ & 0.159 \\
Depression & $7.93 \pm 4.23$ & $7.55 \pm 4.99$ & 0.440 \\
\cline { 2 - 4 } & \multicolumn{3}{|c}{}
\end{tabular}

$* p<0.05$

MAS: Motor Assessment Scale, FIM:Functional Independence Measure, SSQOL: Stroke Specific Quality of Life, HADS: Hospital Anxiety Depression Scale

Table 3. Patient satisfaction results of the patients

\begin{tabular}{l} 
Patient satisfaction scale \\
\hline Complete Improvement \\
\hline Improvement \\
\hline Partially Improvement \\
\hline No Change \\
\hline Symptoms Worsened
\end{tabular}

$n(\%)$

$1(2.1 \%)$

$11(23.4 \%)$

$31(66 \%)$

$3(6.4 \%)$

$1(2.1 \%)$

\section{CONCLUSION}

In our study, we found that the patient-specific physiotherapy program based on neurodevelopmental therapy, was effective on motor recovery and activities of daily living in the short term. However; quality of life, anxiety and depression did not change. This result might due to the short duration of treatment. Although it seems to be a limitation of the disease duration over a wide range of 2-96 months, it is an important result that development can also be achieved in chronic stroke patients. Also, the absence of the control group and the follow-up period is a significant limitation of our study. 